Relation of Corneal Valcularisation and Conjunctival

Transparency to General Disease

\title{
THE RELATION OF CORNEAL VASCULARISATION AND CONJUNCTIVAL TRANSPARENCY TO GENERAL DISEASE*
}

BY

\author{
P. A. GARDINER, Squadron Leader, R.A.F.V.R.
}

THE relation of corneal vascularisation and of conjunctival transparency to nutritional deficiency have already been described (Lyle, Macrae and Gardiner, 1944 ; Gardiner, 1944). The former commun1cation showed that a high limbal score indicating increased corneal vascularisation occurred in groups of people who were living on inadequate or unbalanced diets. The latter investigation showed that increased conjunctival transparency was associated with increased corneal vascularisation and also with inadequate diets. It is hoped to show that these ocular signs are also related to the incidence of disease and therefore that they are useful in the assessment of health.

\section{Plan of experiment}

The eyes of about 190 unselected members of an R.A.F. Hospital. staff were examined with the slit-lamp. A second group was examined which consisted of about 150 Service personnel who were ill. This group was made up of four sub-groups which consisted of patients suffering from :-

$\begin{array}{llllll}\text { 1. Proven duodenal ulcers } & \ldots & \ldots & \ldots & (60)\end{array}$

2. Other chronic gastro-intestinal diseases $\quad \ldots . \quad$ (35)

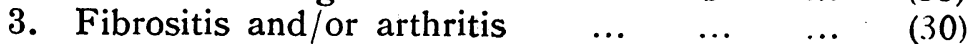

4. Chronic chest or chronic skin diseases ... (19)

In all these sub-groups no subjects with a doubtful diagnosis or double pathology were examined except in sub-group 3, and the condition was in every instance severe enough to warrant their being in hospital or being invalided from the Service. It will be observed that the diseases mentioned are all of a chronic nature. The figures in parentheses are the numbers examined in each group.

The healthy group was under Service conditions and therefore a relatively accurate record of the incidence of sickness could be oBtained since their arrival at the unit. An analysis was made of the number of times each individual in this group had reported sick for any cause except trauma, before the examination. This analysis was made after the examination took place. Investigation showed there were probably only a few cases of concealed or unreported sickness. The mean number of times per quarter that a subject reported sick was termed the sick index. Those subjects

\footnotetext{
* Received for publication, November 27, 1945.
} 
whose records were available for less than three months were not included in the analysis. On an average records were available for 6 months though a considerable number of subjects had records for a year or more. A follow-up was also undertaken for 3 months after the examination.

The results obtained are noted and discussed separately for each ocular sign.

\section{A. - Corneal vascularisation}

The same system of notation was used to assess the vascularity of the limbus as was used in former surveys (Lyle; Macrae and Gardiner, 1944).

Table 1 shows the mean vascularity of the cornea in healthy and iil people:

\section{TABLE I}

$\therefore$ Vascularity of the cornea in the healthy and the diseased

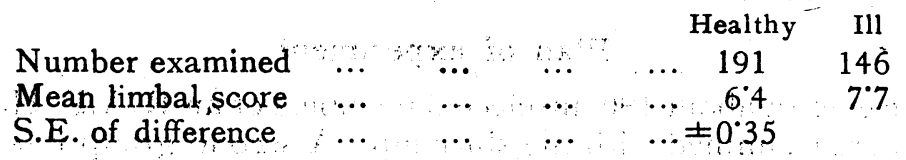

This table indicates a statistically significant difference in the vascularity of the two groups.

Table II shows the sick index of the healthy group correlated with the corneal vascularity.

TABLE II

Correlation of sick index and vascularity (pre-exam.)

\begin{tabular}{|c|c|c|}
\hline $0-5$ & $6-11$ & $12-19$ \\
\hline Number examined $\quad \ldots \quad \ldots, \quad, \quad 76$ & 78 & 13 \\
\hline Mean sick index per quarter & 0.44 & 0.59 \\
\hline $\begin{array}{l}\text { Mean number of months at } \\
\text { Unit before first sick report } 6.2\end{array}$ & $4 \div 5$ & $3: 1$ \\
\hline $\begin{array}{l}\text { Mean number of months at } \\
\text { Unit before first sick report } \\
\text { (excluding those not report } \\
\text { ing) } \ldots\end{array}$ & $3 \cdot 2$ & 23 \\
\hline Per cent. with no sick reports , 43 & & \\
\hline
\end{tabular}


This table shows that a low degree of limbal vascularity was accompanied by a lower sick index and a high degree of vascularity by a higher sick index. Those with a low degree of vascularity were on the average twice as long at the unit before reporting sick, as those with a high degree of vascularity. This figure includes those who did not report sick at all. The results would be more marked if the ultimate period elapsing in these instances were known. They have been included as though they had reported sick on the day of their examination. The latter results as they stand are statistically significant between the group with scores of 0.5 and the group with scores of 12-19.

It will also be noticed that if only those who did report sick are considered, there is a similar difference in the periods after arrival at the unit, before the first sick report was made. Those with high corneal vascularity reported $2 \cdot 3$ months after arrival and those with a low vascularity 3.8 months. The difference in the mean sick index are therefore not entirely due to the numbers who did not report sick in each particular group.

No certain correlation was found between vascularity and subjective impressions of weight changes. The sick index of those who gained weight was 0.31 and those who lost was 0.45 but this was not statistically significant.

No correlation could be obtained between the type of illness reported and the degree of vascularity. The largest type of illness reported was upper respiratory infection. It should be noted that only a negligible proportion reported sick on account of their eyes. There was no correlation between the occurrence of ocular symptoms in the healthy group and the degree of corneal vascularisation.

The sick reports for the three months following the examination were also obtained and the results are shown in Table III

TABLE III

Correlation of sick reforts and corneal vascularity (post-exam.)

\begin{tabular}{lrrr|r|r}
\hline \multicolumn{2}{c}{ Limbal score } & & $0-5$ & $6-11$ & $12-19$ \\
\hline Number examined & $\ldots$ & $\ldots$ & 72 & 80 & 14 \\
Number reporting sick & $\ldots$ & 14 & 24 & 4 \\
Percentage $\quad \ldots$ & $\ldots$ & $\ldots$ & 19 & 30 & 29 \\
\hline
\end{tabular}


The mean sick index was not necessary in this part of the investigation as all the subjects were under observation for all the period. These figures are not statistically significant but it will be noticed that the percentage of those with a low vascularity who reported sick was lower than those with a high vascularity.

\section{Discussion}

Some of these results are statistically significant; viz, the corneal vascularity of the ill group was significantly higher than of the healthy group (Table I), the length of time before reporting sick was significantly greater in those with low degrees of vascularity than in those with high degrees of vascularity (Table II). The remaining results are not significant statistically but they fall into line with and reinforce the conclusions which are to be drawn from the significant results. The broad conclusion is that in disease the degree of corneal vascularisation increases. This conclusion rests on the following results as well as on the statistically significant results.

The three months' follow up indicates that there is a probability that those with higher degrees of vascularity will report sick in greater numbers than those with a low degree of vascularity. The analysis of the sick reports before the examination shows that those with a high degree of vascularity reported sick in greater numbers than those with a low degree of vascularity. In the former case the proportion of those reporting to those not reporting was about 6 to 3 and in the latter case about 4 to 3 .

It has already been shown that there is some connection between the degree of corneal vascularisation and states of nutritional deficiency. It is consistent with this that there should be a connection between morbidity and corneal vascularisation. Only a very small proportion of the illnesses recorded in the healthy group were of a kind which would directly and obviously be associated with nutritional or metabolic disorders.

The results are interesting in other ways. First they indicate that examination of the eyes brings to light signs frequently associated with common constitutional diseases. Secondly, the results seem to indicate that the normal cornea is the one which is least vascularised. The exact limit of normality has not yet been established and must still remain in doubt. It is worth noting that a score of less than 6 indicated that no vessels encroach on the clear cornea and it may be that this is the real normal or optimum. Thirdly, the consistence of these results indicates that the system of notation adopted is not unrelated to a true measurement of the degree of vascularity seen. In the great majority of cases the measurement presents no difficulty and the system can be learnt quickly by anyone who is used to the slit-lamp. 
Relation of Corneal Vascularisation and Conjunctival

Transparency to General Disease

\section{B.-Conjunctival transparency}

The technique of examining the conjunctiva and the method of grading the degree of transparency has already been described in a previous communication (Gardiner, 1944). A standard graph which showed the mean transparency in 2,500 healthy subjects at various ages was used as a basis of normality in the present investigation. The present results are tabulated so that the subjects fall into three groups, viz, transparency above average; average; and below average. Subjects over 30 years old show less variability in the transparency of the conjunctiva and therefore have not been included.

The same groups were examined as in the first part of the investigation and the following results were found.

TABLE IV

Conjunctival transparency in the healthy and the diseased

\begin{tabular}{l|r|r|r|r}
\hline & \multicolumn{2}{|c|}{ Healthy } & \multicolumn{2}{|c}{ Ill } \\
\cline { 2 - 4 } & No. & Per cent. & No. & Per cent. \\
\hline & & & \\
\hline Above average & 74 & 42 & 35 & 56 \\
Average... & 73 & 41 & 23 & 37 \\
Below average & 31 & .17 & 4 & 7 \\
\hline
\end{tabular}

Table IV shows the difference in the distribution of subjects in the healthy and sick groups according to the transparency of their conjunctiva.

Table $\mathrm{V}$ correlates the conjunctival transparency in a healthy group of people with the sick incidence.

The figures relating to the number of months before the first sick report do not include the subjects who did not report sick.

This table shows that the rate of sickness amongst those with a high conjunctival transparency was high compared with the rate in those subjects who had a low transparency. The proportion not reporting sick to some extent accounts for this difference. Those with an average transparency show an intermediate incidence of sickness.

None of these results is statistically significant. No correlation was found between subjective impressions of weight changes and the conjunctival transparency. 
P. A. GARDINER

TABLE V

Correlation of sick index and Conjunctival Transparency (pre-exam.)

\begin{tabular}{|c|c|c|c|}
\hline \multirow{2}{*}{ a } & \multicolumn{3}{|c|}{ Conjunctival Transparency } \\
\hline & Above average & Average & Below average \\
\hline Number examined $\ldots$ & 58 & 54 & 21 \\
\hline Mean sick index per quarter & 0.48 & 0.42 & 0.29 \\
\hline Mean number of months at & & & \\
\hline Unit before first sick report & 24 & $2 \cdot 9$ & $4 \% 5$ \\
\hline Per cent. not reporting sick & 28 & 35 & 48 \\
\hline
\end{tabular}

Table VI shows the incidence of sickness occurring after the examination.

\section{TABLE VI}

Correlation of sick index with Conjunctival Transparency (post exam.)

\begin{tabular}{|c|c|c|c|}
\hline \multirow{2}{*}{$=\quad \vdots$} & \multicolumn{3}{|c|}{ Conjunctival Transparency } \\
\hline & A bove average & Average & Below average \\
\hline Number not reporting sick... & $\therefore 42$ & 35 & 15 \\
\hline Number reporting sick & 13 & 14 & 9 \\
\hline Yer cent. reporting sick & $\therefore \quad 24$ & 29 & 38 \\
\hline
\end{tabular}

This table shows that after the examination those with a transparency below average reported sick more frequently than the others. The figures are not as large as in the preceding tables and again are not significant statistically.

\section{if Discussion}

The results obtained indicate that the transparency of the conjunctiva has some relation to the health of the individual As in the instance of the corneal vascularity there was no correlation with 
any particular type of disease and although it has been shown that the conjunctival transparency is probably connected with nutritional well being the diseases reported amongst the healthy group were not likely to be of a nutritional origin. The results recorded in Table IV indicate that the transparency is increased in chronic disease and those in Table $\mathrm{V}$ indicate that a higher incidence of trivial sickness is also accompanied by an increase in transparency of the conjunctiva. These results are not sufficiently clear cut to render a dogmatic conclusion possible especially in view of the conflicting results obtained after the examination and in the absence of statistical confirmation in Table $\mathrm{V}$. The figures in Table VI are so small in the " below average" group as to be almost worthless. However, it seems probable that the conjunctival changes are not very abrupt and therefore not as sensitive an index over a short term as the vascularity of the cornea.

The combination of a high vascularity and a high transparency occurred too seldom to be compared with a low transparency and low vascularity.

\section{Conclusion}

The results obtained from this investigation indicate that slitlamp examination of the conjunctiva and cornea provides a clue to the amount of trivial sickness amongst a group of people over a period varying between three months and two years before examination and also to the amount of sickness they are likely to suffer from in the three months after examination. It is possible to say that those with a high degree of corneal vascularity are as a group more likely to report sick than those with a low degree of vascularity. The conjunctival results must be considered with more reserve but those with a high transparency reported sick nearly twice as often before examination as those with a low transparency.

The investigation provides very little help in determining the type of illness which influences these signs. It has alsa failed to indicate any normal level of corneal vascularity. There may be wide individual limits but it is probable that in health the cornea is less likely to be vascularised than in illness. In the present series, however, there were a few subjects with high degrees of vascularity who did not report sick at all. The slit-lamp has already proved its worth in nutritional surveys in the R.A.F., and the present results indicate a somewhat broader field of action in which it may assist.

\section{Summary}

The degree of conjunctival transparency and of superficial vascularisation of the cornea are shown to be higher in chronic disease than in health. The degree of superficial vascularisation of the 
cornea and the degree of transparency of the conjunctiva are shown to have a relationship to the incidence of sickness in a group of healthy people.

My thanks are due to Group Captain W. A. S. Duck, O.B.E., Commanding Officer of the R.A.F. Hospital, Northallerton, for his permission to carry out this investigation and also to the Staff of the hospital for their co-operation. The Director General of the Royal Air Force Medical Service has kindly given his permission for publication of this paper.

\section{REFERENCES}

GARDINER, P. A. (1944).-Brit. Jl. Ophthal., Vol. XXVIII, pp. 11, 538.

LYLE, T. K., MACRAE, T. F. and GARDINER, P. A. (1944).-Lancet I, p. 393.

\section{OCULAR DECOMPENSATION*}

BY

E. M. G. GALton, Major, R.A.M.C.

THE attitude towards the significance of refractive errors, accommodative anomalies and abnormal ocular muscle balance has changed considerably during the past few years. This change has been accelerated by the experience of a certain type gained in the armed forces. In them large numbers of individuals of both sexes were seen, who, in the ordinary course of events would never have presented themselves for examination. These cases fall into two groups (1) men and women whose visual acuity was found, during routine testing, to fall below required Service standards. (2) Those with headache as the main symptom. This is probably the commonest single complaint met with in the army and is much more frequent than among civilian patients. As very few are allowed to escape an examination for "a refractive error" the number in this group is very large. It may be mentioned in passing that it was in only the minority that an ocular cause for the headache could be substantiated.

When reviewing numbers of cases of these types it is immediately obvious that the majority had been able to do their civilian work quite happily and without difficulty in the presence of refractive errors of all grades very often with some heterophoria as well. It was only when called upon to do other types of work or the same work under less favourable conditions that some of them developed symptoms.

In other words ocular symptoms are due not so much to the

* Received for publication, September 19, 1945. 